\title{
The Labor Cost Management of Marine Engineering Project Based on Activity-Based Costing Method
}

\author{
Xiaoping Ma ${ }^{1}$, Minyu $\mathrm{Yan}^{2 *}$, Biao $\mathrm{Yao}^{3}$ \\ ${ }^{1}$ School of Naval Architecture and Ocean Engineering Jiangsu University of Science and Technology line Jiangsu \\ Zhenjiang, China \\ ${ }^{2}$ School of Naval Architecture and Ocean Engineering Jiangsu University of Science and Technology line Jiangsu \\ Zhenjiang, China \\ ${ }^{3}$ Jiangsu Modern Shipbuilding Technology Co., Ltd. Jiangsu Zhenjiang, China \\ * Corresponding author: Yan Minyu \\ e-mail address: $1414738636 @ q q . c o m$
}

\begin{abstract}
In view of the shortcomings in the labor cost management of marine projects, the feasibility of the integration of target cost method and activity-based cost method is analyzed. The target cost is decomposed step by step according to the product oriented job decomposition structure to form a top-down, hierarchical compressed labor target cost control process. Taking the task package as the object of labor settlement, collecting labor costs and monitoring cost status. The accumulated performance cost data is used as the basis for the subsequent estimation of the labor cost of the project, and the labor cost management system of circular control is formed, which improves the labor cost management level of marine engineering projects.
\end{abstract}

Keywords: marine manufacturing, quota, WOP, target cost, ABC

\section{INTRODUCTION}

Labor cost refers to the used in the project put into production directly artificial cost of labor, it is an important component of the offshore manufacturing enterprise cost, made by Yu Haigong particularity of the project, offshore manufacturing enterprise labor cost management difficulty is big, especially the shortage of human resources, more need to strengthen the control of labor costs.

The traditional target cost method is difficult to accurately determine the target cost of new Marine products and the cost target decomposition is difficult [1]. However, activity-based costing cannot accurately reflect the relationship between contract price, target profit and target cost, and is not conducive to managers' management decisions. By integrating the target cost method and activity-based cost method, the management decision needs can be met, and the limitations of single cost method can be overcome at the same time, which is conducive to accurate cost control. Decompose the target cost to the job step by step according to the product-oriented activity decomposition structure (PWBS) [2]; And take the task package as the cost accounting object, collect, analyze and clean the actual labor cost information, feedback and control the formulation of the project target cost, and form the labor cost management system of circular control [3].

\section{ANALYSIS ON THE PRESENT SITUATION OF LABOR COST MANAGEMENT OF MARINE ENGINEERING MANUFACTURING PROJECT}

Marine engineering products have typical discrete characteristics such as complex structure, intensive technology, specialty intersecting and long cycle. Therefore, its labor cost management has the following characteristics: long management process cycle, labor cost plan with the design of refinement, involving more types of work. The management of labor cost is an important link in the cost management of Marine engineering projects. After investigating the current situation of cost management of a Marine engineering enterprise, the business process of labor cost management is shown in Figure 1: 


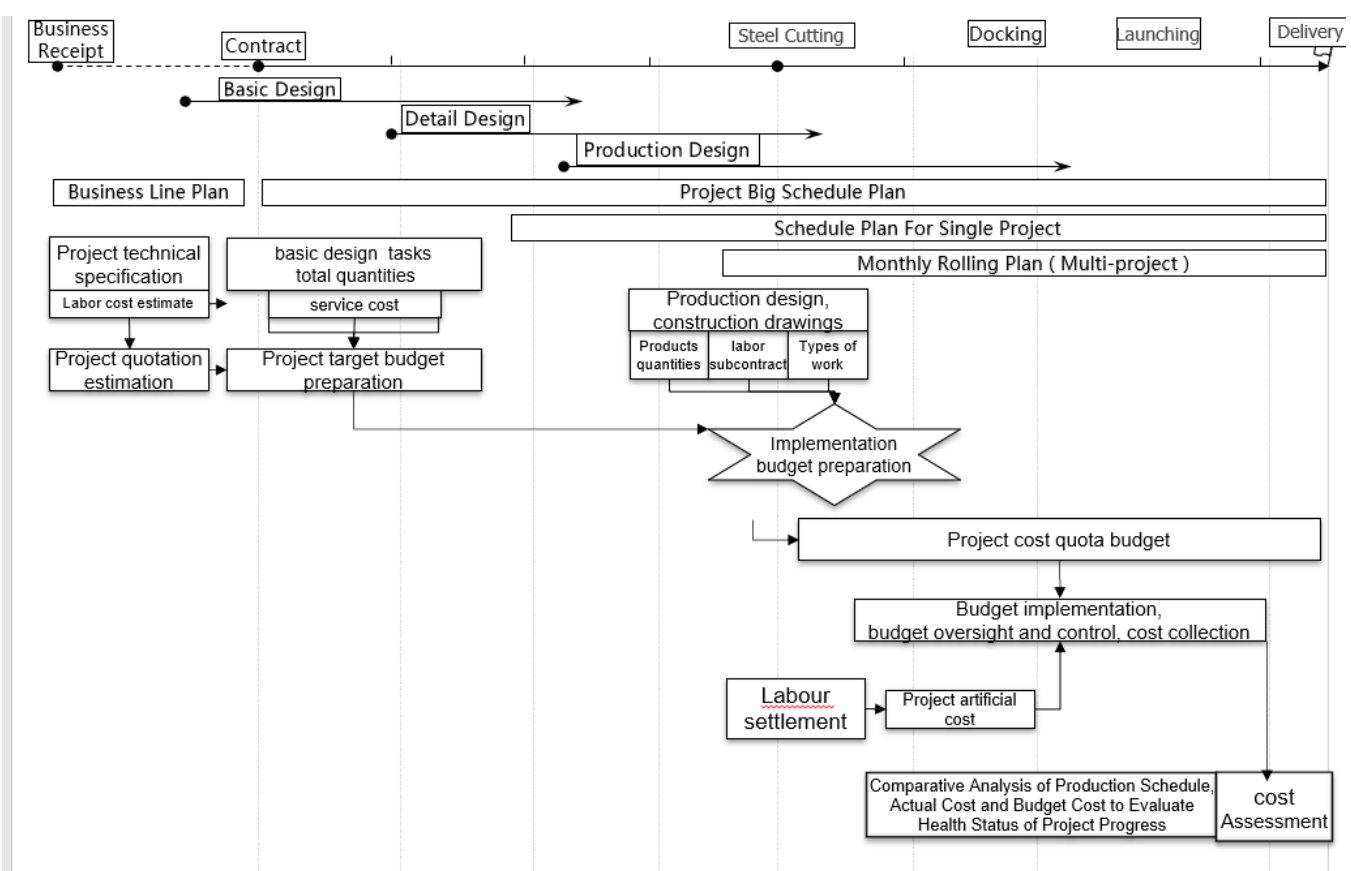

Fig. 1 Marine engineering project labor cost management business process

Through the investigation and analysis of the labor cost business of Marine engineering projects, it is found that there are mainly the following problems: 1) It is difficult to calculate the labor price quota of enterprises, which leads to a large gap between the labor cost estimated by quotation and the actual cost. 2) estimation budget estimate - implementation budget - quota budget settlement deviation is large, the number of budget adjustment. 3) The actual labor cost information statistics are not timely. 4) Insufficient comparative analysis of man-hour - labor cost - labor efficiency. In view of the above problems, based on the actual business of labor cost management in Marine industry enterprises, through the integration of target cost and activity-based costing, the labor cost management system of Marine industry projects based on target activity-based costing is constructed and the labor cost management process is standardized.

\section{THE DECOMPOSITION OF JOB - BASED LABOR TARGET COST}

\section{1. .Feasibility analysis of integration of objective costing method and activity-based costing method}

Target cost method is based on a given price to determine the target cost of products, in order to achieve the expected profit[4]. The three links are 1) to determine the target, layer by layer decomposition. 2) Real-time targets, monitoring performance appraisal. 3) Evaluate objectives, reward and punishment. The advantage of the target cost method lies in that it sets the total target profit of the project at the beginning, which meets the needs of the enterprise development strategy. At the same time, by dividing the target cost into the responsible department, only the responsible department needs to carry out cost assessment. But the establishment of the target cost needs to accurately estimate the actual cost of the product.

Activity-based Costing (ABC) is Based on activity-based Costing and its core concept is "product consumption activities and Activity consumption resources"[5]. The advantage of activity-based costing is that it can accurately calculate the actual cost of the whole project from the bottom up through specific operations, which is helpful to improve cost control and provide information support for strategic management. But it is not conducive to enterprise financial management needs, cannot accurately reflect the target profit in advance, is not conducive to enterprise strategic planning.

By integrating the target cost method and activity-based costing method, the target cost can be decomposed from top to bottom according to the activity-based decomposition structure of the product, until the specific task package. Then cost accounting is carried out from bottom to top by activity-based costing method. In this way, the total target profit of the project can be controlled to facilitate the management needs of enterprises; It also conforms to the actual business process that the cost of Marine engineering project is refined with the deepening of product design. At the same time, with the application of information technology in Marine engineering enterprises, especially the extensive application of task assignment and report system in Marine engineering project management, it brings great convenience for the collection of actual costs. The actual cost information collected is analyzed and processed to form the enterprise labor cost quota system, which can be 
used to estimate the actual cost of products and provide reliable basis for the development of reasonable and accurate target cost. Therefore, the integrated application of objective cost method and activity-based cost method in labor cost management of offshore engineering project is feasible.

\subsection{A target cost decomposition model based on PWBS}

The integrated application of activity-based costing method and target costing method in the labor cost management of offshore engineering projects can not only reflect their respective advantages, but also make up for each other's shortcomings. The product-oriented job decomposition structure of offshore manufacturing project is based on the product decomposition structure (PBS) to carry out job decomposition (WBS), or PWBS for short. To decompose Marine products according to their product decomposition structure and to decompose the operations needed to complete intermediate products at all levels. Through layer by layer decomposition, the entire production task is decomposed into the appropriate task package (WOP) [6]. Based on PWBS structure, the labor target cost of Marine engineering project is decomposed, refined and controlled step by step. Its model is shown in Figure 2:

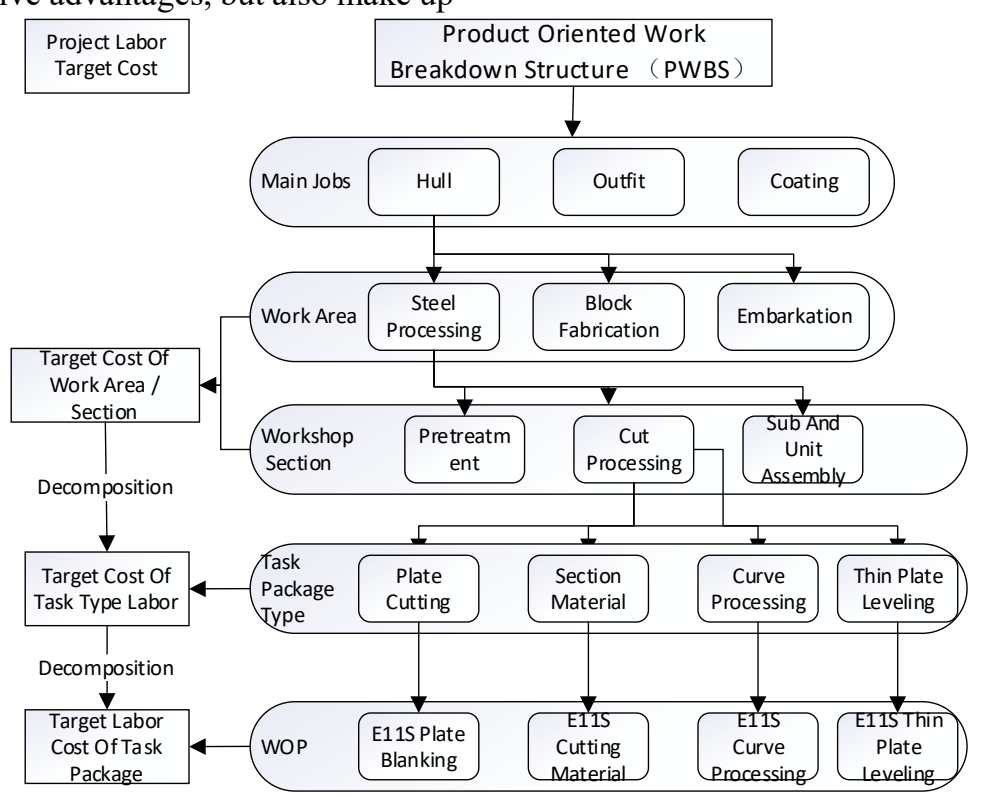

Fig.2 Labor target cost decomposition based on PWBS1

The product-oriented job decomposition structure of Marine engineering is divided into five levels: large work type, work area, work section, task package type, and WOP. In the early stage of the project, due to incomplete project data, the labor cost of each work area/work section can only be estimated, and relatively rough labor target cost can be worked out according to the contract and target profit. With the progress of the project, the improvement of the design data and the subcontracting of work, the labor target cost of the working area is decomposed into various types of tasks to form the labor target cost of each type of task. Finally, the labor target cost is decomposed into specific WOP to form the labor target cost of each WOP.

\section{THE LABOR COST MANAGEMENT SYSTEM BASED ON TARGET OPERATION}

Based on the actual business process of labor cost management of Marine engineering project, the paper applies target activity-based cost management (TABC) to establish the correlation relationship between the cost information of labor cost in various time stages from estimation, target estimate, execution budget, quota budget, cost collection and cost analysis. The labor cost of the project according to the work breakdown structure product oriented by the decomposition, the labor cost on the space allocated to each homework, and through the work, to establish contact with all the cost code to the whole project labor costs in time - space online build relationships, building a comprehensive, standardized Marine engineering labor cost of the project management system. Labor cost management flow chart of marine manufacturing projects is shown in Figure 3: 


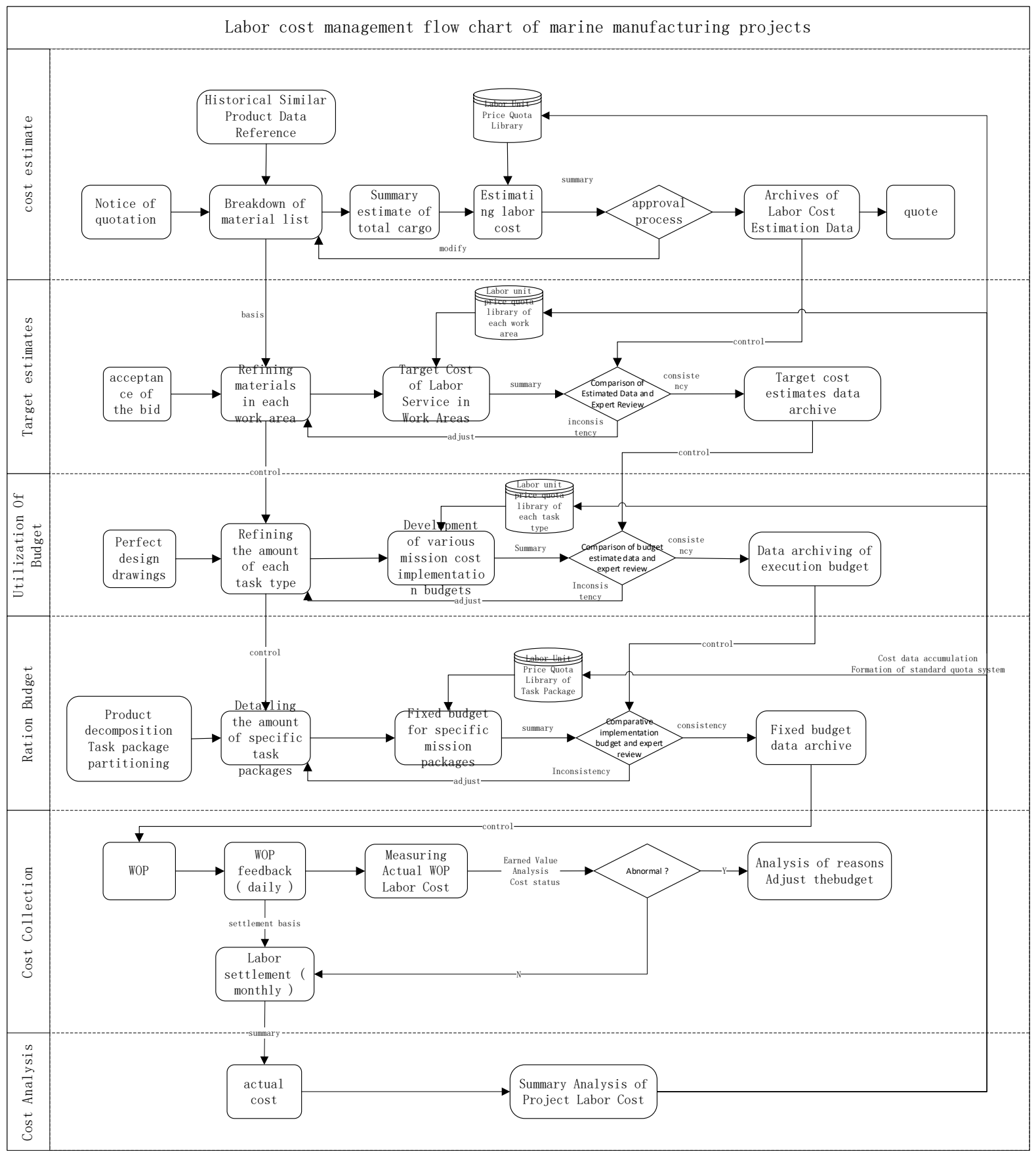

Figure 3. Process of labor cost management system of offshore engineering project

The labor cost management of Marine engineering project is mainly divided into six stages: cost estimation, target estimate, execution budget, quota budget, cost collection and cost analysis. With the improvement of the project design data, the target cost of the whole project labor cost is decomposed into the work area/section, task type, specific task package in turn according to the PWBS structure, and the labor target cost is controlled step by step. And through the docking with the labor settlement, the actual cost is collected by the task package as the unit; Finally, the cost information is analyzed and the standard service quota knowledge base is formed, which is used as the basis for the follow-up project service cost estimation and budget. Forming the labor cost circulation control system. The following is a detailed analysis of the labor cost control process at each stage:

\subsection{Estimation of labor cost based on standard quota pool}

Cost estimation mainly estimates the cost of the project to be quoted, and is used as the basis for the quotation [7]. After receiving the notification of project quotation, we studied the information provided by the ship owner carefully, analyzed the demand, and analyzed the project by combining the data of similar products in the historical project information database to get the 
estimated list of various materials of the whole ship. The quantity of materials is $\mathrm{m}=\left\{\mathrm{m}_{1}, \mathrm{~m}_{2}, \mathrm{Mn}\right\}$; Based on the quota database of labor cost, the unit labor price $\mathrm{P}=\{\mathrm{P}$, $\left.\mathrm{P}_{1}, \mathrm{P}_{2}\right\}$, then the labor cost corresponding to its materials $\mathrm{c}=\mathrm{m}^{*} \mathrm{p}$, and the project cost set is $\mathrm{c}=\left\{\mathrm{c}_{1}, \mathrm{c}_{2}, \mathrm{C}_{\mathrm{n}}\right\}$, according to CBS summary to form items-total labor cost estimation list, submitted to professional management personnel for review; If not, it is necessary to modify and adjust the quantity and unit price again until it is confirmed to be approved. Passed as the basis of labor cost quotation estimation, assist the management to make the final quotation, and also used to develop the basis of labor target cost estimate.

\section{4..The formulation and decomposition of labor target cost}

With the progress of the project, the detailed design and production design will be improved. In the stage of cost target estimate, execution budget and quota budget, the target cost is decomposed and controlled with section, task package type and specific task package as the object.

\subsubsection{Labor target cost estimate}

Make target profit according to enterprise strategic development plan, and make target labor cost based on labor cost estimation; At this stage, after the bid is won, the preliminary design data are relatively perfect, but the detailed design and production design data are not perfect enough. The labor target cost of the project generally takes the working area/section as the main body of responsibility, and the amount of material required during the estimation is refined to each working area/section, which is controlled by the amount of material during the estimation. The labor price per unit quantity of each working area/section is given through the labor quota database formed by historical data, and the labor cost of each working area is summarized, compared with the estimated labor cost data for control, and submitted to professionals for review; Revise and adjust the unreasonable part until it is reasonable and take it as the benchmark to control the labor cost and implement the budget.

\subsubsection{Labor target cost implementation budget}

Before and after the commencement of the project, with the development of the design, the subcontracting of the project has been basically determined, but the drawings of the intermediate products and the specific task package cannot be provided. At this time, according to the quantity of goods, subcontracting the implementation of the budget labor costs; The establishment of the executive budget needs to form a relatively accurate and complete budget; Firstly, according to the drawings, the material quantity of each working area/section is subdivided into various tasks to form a set of material quantity of the whole ship with the same task type, and the task target cost is formulated and the budget is implemented through the labor quota and unit price database of each task type. The material quantity and cost of all task types under the working area are summarized and compared with the target cost estimate, which shall meet the target cost of all tasks under the working area and the target cost of the working area when the target cost is not more than the estimate; At the same time, experts are required to review the target cost of each task type and adjust and modify the unreasonable parts. Finally, a reasonable and accurate target implementation budget is developed, which is used to develop and control the target cost quota budget.

\subsubsection{Labor target cost quota budget}

Quotation budget is to calculate the labor cost of specific task package based on the quantity of material of specific task package and the unit price of labor quota corresponding to the quantity of material of specific task package after the technical department can provide the drawings of intermediate products and the quantity of material of specific task package. By summarizing the material amount and labor cost of all the WOP of the project under the PWBS structure of the same type of task, it cannot be more related to the implementation of the budgeted target.

Through the decomposition of the labor cost of the whole project at each stage above, the target cost of the whole project is decomposed into the work area/section, task type and WOP level according to the PWBS structure. The corresponding responsible subjects are the corresponding departments of the work area/section, and the task type and WOP correspond to the corresponding construction team. In this way, the decomposition of labor target cost not only confirms the responsibility subject, but also facilitates the management of the project. At the same time, the total target cost which is difficult to measure for the whole project is decomposed into the target cost of WOP which is easy to measure. By realizing the target of WOP and controlling the decomposition process, the labor cost target of the whole project is finally completed.

\subsection{Labor cost collection based on WOP}

Through the above labor target cost decomposition, the labor target cost of the whole project is specifically decomposed into WOP; Then by taking WOP as the object of cost collection, the actual cost is collected and summarized step by step, and finally the labor cost structure tree of the project is formed. The WOP execution process of Marine engineering project is shown in Figure 4: 


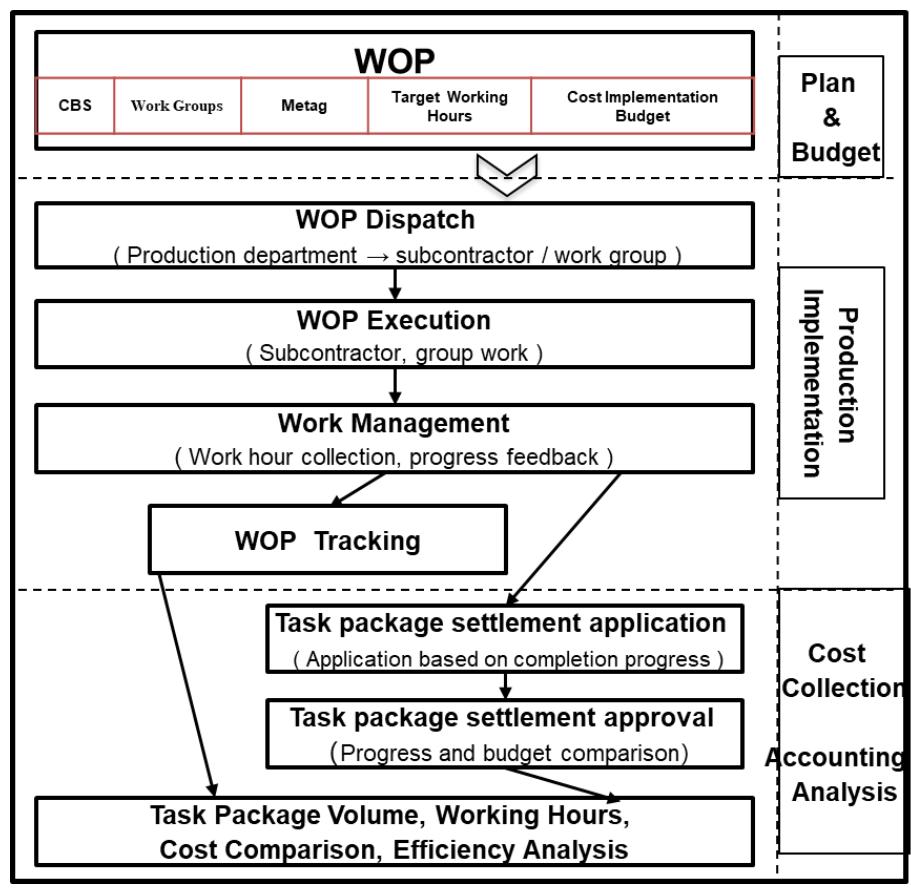

Figure 4 Wop execution flow

First of all, the WOP containing the target working hours, target cost, material quantity and other information is sent to the operation group through the information system. After the completion of the operation group every day, the actual working hours and progress information will be fed back according to the actual situation. The collection of actual labor cost is based on the feedback information of WOP, and the actual working hours and progress information of all task packages under it are summarized according to different dimensions through the feedback information of WOP. The actual labor cost of WOP was estimated based on the labor price per unit of actual man-hour, and the earned value method was applied to evaluate the operation based on the feedback progress of the task package to monitor the actual cost and adjust and control the abnormal cost in time. The advantage of the actual cost calculated based on the working hours reported by the workers is the daily feedback and the timely collection of cost information, which is conducive to the monitoring of the labor cost state. The disadvantage is that the feedback time is not the actual cost, because the enterprise will reward and punish the completion of WOP according to the completion of the target cost of WOP. Therefore, in the end, the actual labor cost consumed by WOP will be subject to the actual labor settlement, and the total labor cost information of the project will be formed according to the summary from the bottom right to the top of the decomposition structure of WOP.

\subsection{Cost analysis}

With the actual cost information of the task package as the settlement unit, the task package can be summarized according to the PWBS structure through the PWBS information contained in WOP encoding to form a multi-dimensional cost analysis. For example, according to the work area, it can be divided into processing, erecting, carrying and final assembly, etc.; according to the work section, it can be divided into groups, large groups, pre-outfitting in sections, and closing, etc.; it can also be summarized and displayed according to the task type and intermediate products, etc., to analyze the causes of cost differences and trace the cost responsibility of the corresponding responsible subjects. The ergonomics analysis table by task type is shown in Table 1:

Table 1 Ergonomics analysis table

\begin{tabular}{|c|c|c|c|c|c|c|c|}
\hline Task type & $\begin{array}{c}\text { Target } \\
\text { execution } \\
\text { budget (ten } \\
\text { thousand } \\
\text { yuan) }\end{array}$ & $\begin{array}{c}\text { Target } \\
\text { budget } \\
\text { (ten } \\
\text { thousand } \\
\text { yuan) }\end{array}$ & $\begin{array}{c}\text { Settlement } \\
\text { Amount } \\
\text { (ten } \\
\text { thousand } \\
\text { Yuan) }\end{array}$ & $\begin{array}{c}\text { Construct } \\
\text { ion Hours } \\
\text { (Hours) }\end{array}$ & $\begin{array}{c}\text { Cost } \\
\text { incurred } \\
\text { (ten } \\
\text { thousand } \\
\text { Yuan) }\end{array}$ & $\begin{array}{c}\text { Proporti } \\
\text { on of } \\
\text { progress } \\
\text { (\%) }\end{array}$ & $\begin{array}{c}\text { Ergon } \\
\text { omics } \\
\text { (yuan/ } \\
\text { hour) }\end{array}$ \\
\hline $\begin{array}{c}\text { Blanking sets } \\
\text { match }\end{array}$ & 390.53 & 163.55 & 106.02 & 16239.50 & 48.72 & 12.47 & 30.00 \\
\hline $\begin{array}{c}\text { Group } \\
\text { production }\end{array}$ & 3470.57 & 1837.51 & 1108.70 & 291993.5 & 1167.97 & 33.65 & 40.00 \\
\hline
\end{tabular}




\begin{tabular}{|c|c|c|c|c|c|c|c|}
\hline $\begin{array}{c}\text { Large group } \\
\text { to make }\end{array}$ & 12942.57 & 5488.28 & 2605.44 & 373170.7 & 1546.97 & 11.95 & 41.45 \\
\hline $\begin{array}{c}\text { Piecewise } \\
\text { pre-outfitting }\end{array}$ & 2799.28 & 801.04 & 490.88 & 220545.7 & 992.46 & 35.45 & 45.00 \\
\hline $\begin{array}{c}\text { Closed } \\
\text { production }\end{array}$ & 7863.95 & 525.25 & 328.26 & 87335.50 & 408.60 & 5.20 & 46.79 \\
\hline $\begin{array}{c}\text { Iron } \\
\text { snoop-proof }\end{array}$ & 1168.42 & 173.47 & 80.47 & 52455.00 & 209.82 & 17.96 & 40.00 \\
\hline
\end{tabular}

With the accumulation of project information, the abnormal cost information is cleaned at the same time to form the standard material quantity - contract employees fee standard quota system; For example, the calculation method of labor cost quota in a working area: by collecting the material quantity, actual working hours and actual settled labor cost contained in all the WOP in the working area, the linear relationship between material quantity, working hours and labor cost can be analyzed by linear regression analysis method; With the increase of the amount of data can also use artificial neural network algorithm, analysis of its nonlinear relationship, more accurate to develop a more accurate quota system. Then, based on the quota analyzed by cost information, the actual cost of the new project can be estimated more accurately and the management can be assisted in formulating reasonable target cost.

\section{CONCLUSION}

In Marine engineering project, analyzing the present situation and problems of labor cost management for labor cost estimation budget basis, actual cost information collection is not timely, such problems as lack of efficiency analysis, build a Marine engineering project services based on homework cost method target cost management system, through the accumulation of cost data form the standard labor quota, used for the basis of labor cost estimation, Can solve the enterprise labor cost estimation and the actual cost gap, budget is not allowed and other problems. Through the connection with the WOP report, the labor cost information can be collected in real time to realize the real-time monitoring and early warning of the cost status. The cost completion analysis provides the basis for the follow-up development of reasonable and accurate labor target cost, and forms the labor cost management system of circular control.

\section{REFERENCES}

[1] Wu Shuijuan, Li Wenchang, Ge Shilun. Shipbuilding Technology,2004(02):16-19. (in Chinese)

[2] Sun Lingfang, Wang Nianxin. Research on Dynamic Control System of Target Cost in the Whole Process of Shipbuilding [J]. Shipbuilding Engineering, 2006(05):111-114.

[3] Li Youzhu, Ma Xiaoping. Research on Man-hour Quantity Quota System in Shipbuilding [J]. China Water Transport (Second Half),2014,14(10):8-10-13.

[4] Yao Xiaohua, Ou Weihui. The practice of target cost management system in new shipbuilding industry $[\mathrm{J}]$. $\quad$ Finance and Accounting,2018(24):31-33.

[5] Wu Junmin, Wei Xiaozhuo, Ning Xuanxi. Target cost control of shipbuilding enterprises based on activity-based cost [J]. Shipbuilding of China,2008(02):127-134

[6] Ma Xiaoping, Gao Ke, Yao Biao. Application of Multi-level Earned Value Method in Shipyard Operation Schedule Control [J]. Ship Engineering,2019,41(09):21-25.

[7] Chen Zhandou. Research on the Supplier Management Strategy of Shipbuilding Enterprises from the Perspective of Management Accounting [J]. Journal of Jiangsu University of Science and Technology (Social Science Edition), 2018,18(01):82-88. 